\title{
Predicting Epidemic Diseases using Mathematical Modelling of SIR
}

\author{
K. ERGEN ${ }^{a}$, A. ÇILli ${ }^{b * *}$ AND N. YAhnioĞLU ${ }^{c}$ \\ ${ }^{a}$ Bülent Ecevit University/Biophysics Department, Zonguldak-Türkiye \\ ${ }^{b}$ Yildiz Technical University/Physics Department, İstanbul-Türkiye \\ ${ }^{c}$ Yildiz Technical University/Mathematical Eng. Department, İstanbul-Türkiye
}

\begin{abstract}
Epidemic diseases such as Tuberculosis (TB), AIDS (Acquired Immune Deficiency Syndrome) and CCHF (Crimean-Congo Hemorrhagic Fever) remain as a major global health problem. For example, in 2012, an estimated 8.6 million people developed TB and 1.3 million died from the disease reported by WHO (including 320000 deaths among HIV (human immunodeficiency virus) positive people) in the world. However, the presence of immunodeficiency such as in HIV positive cases helps TB to occur and to be contagious. Hence, to decrease the number of patients with TB lessens the socioeconomical burden, and, to prevent the people from TB as well as TB/HIV and MDR-TB (multi-drug-resistant tuberculosis) are of importance. Taking appropriate precautions in fighting epidemic diseases begins primarily with making predictions. In this respect, although the diagnosis and cure are known for some epidemic diseases, it is evident that a fighting program must depend on predictable cases. Therefore an investigation on an epidemic disease in framework of the mathematical modelling is indispensable and can potentially lead to better ways to analyze, forecast, and prevent epidemics. In this study, to help with all these concerns, we aimed to predict the effects of epidemic of TB including HIV positive patients, as well as of AIDS and CCHF in terms of number of infected people in Turkey by using the mathematical modelling of SIR. Here, we showed that SIR (susceptible-infected-recovered) Model can be used for such epidemic diseases.
\end{abstract}

DOI: 10.12693/APhysPolA.128.B-273

PACS: 87.19.X, 89.65.Cd

\section{Introduction}

Epidemic diseases have been an important problem for mankind. It is estimated to account for $43 \%$ of the global burden of disease where the burden of health is measured in the number of years of healthy life lost [1]. Although epidemic diseases have impacts on every age of history of human being, it has a greater effect in certain periods. For example, The Black Death of 1347-1351, provides one of the tragic historical examples of an infection with high mortality, claiming an estimated $30-50 \%$ of the European population in only a five-year period [2]. Moreover, it cannot be denied that epidemic diseases have a negative impact on both business life and production. It also leads to immigration for fear of life.

Scientists have always been searched for the right methods to fight against epidemic diseases. Although success has been provided to some extent with antibiotics, vaccines and other methods, still it has not been possible to remove these kinds of diseases completely. Bacteria causing tuberculosis and plague have gained antibiotic resistance and re-emerged in the course of time. Moreover, Lyme disease [3], Legionella [4], AIDS [5], Hepatitis C [6], Severe Acute Respiratory Syndrome (SARS) [7] are the epidemic diseases appearing in recent years.

\footnotetext{
*corresponding author; e-mail: acilli@yildiz.edu.tr
}

Fighting with epidemic diseases primarily begins prior to epidemia. Taking appropriate precautions and foreseeing the impact of the diseases are of importance to reduce/ minimize the negative social and economic effects. For this reason, mathematical models are used and the $S I R$ model is the one that is widely used to represent infectious diseases such as influenza, SARS, measles, and mumps in which one shot epidemic waves can occur and the mortality is high or the recovery implies immunity [7]. In this project we aimed to predict the effects of the some epidemic diseases in terms of the number of infected people by using $S I R$ mathematical model.

In this respect AIDS, crimean-congo hemorrhagic fever (CCHF) and tuberculosis were studied as model diseases. Predictive power of the modelling was determined to confirm their reliability and robustness.

\section{Material and methods}

\subsection{SIR epidemiological model}

The mathematical epidemiological model that is probably the most widely used for theorizing about and emulating epidemics is the $S I R$ model $[9,10]$. This model is done by an iteration calculation. In this model, which is effectual for epidemic diseases, the simplest version without demographic factors is defined as follows: It is assumed that there is no death, no birth in the population, no migration into and out of the population and infected people are not re-infected after they have recovered. In the $S I R$ model, each individual belongs to either a susceptible $(S)$, infected $(I)$, or recovered $(R)$ state with 
immunity at any given time. Thus, model can be shown as $S \rightarrow I \rightarrow R$. When a susceptible individual and an infected individual interact, the former may be infected at an infection rate, denoted by $\beta$ constant. In this way, susceptibility is the same for each individual. By accepting these rules following equations are obtained;

$$
\begin{aligned}
& N=S(t)+I(t)+R(t), \\
& \frac{\mathrm{d} S}{\mathrm{~d} t}=-\beta S(t) I(t) . \\
& \frac{\mathrm{d} I}{\mathrm{~d} t}=\beta S(t) I(t)-\gamma I(t), \\
& \frac{\mathrm{d} R}{\mathrm{~d} t}=\gamma I(t) .
\end{aligned}
$$

$N$ in Eq. (1) is constant, what means that the population does not change with time.

For these equations, firstly $\gamma$ is found as follows;

$$
\gamma=\frac{1}{I(t)} \frac{\mathrm{d} R}{\mathrm{~d} t} \text {. }
$$

Then by using the following equation $\beta$ is calculated;

$$
\frac{\mathrm{d} I}{\mathrm{~d} t}=\beta S(t) I(t)-\gamma I(t) \text {. }
$$

For Eqs. (2) and (3), we accept the number of people leaving from the susceptible group is equal to incoming people to infected group. In the mean time infected people can recover and this average recovering ratio is symbolized as $\gamma$ where $1 / \gamma$ denotes average infectious period. When time $t$ closes to infinity, $S$ and $R$ approach to ' $O$ ' and ' $N$ ', respectively. For resolving of the differential Eqs. (2)-(4) the Euler method is used.

The susceptible individual contacts infected individual with probability $\beta$ within a short time interval $\Delta t$. With probability $1-\beta \Delta t$, the susceptible individuals stays in the susceptible state throughout the interval $\Delta t . \Delta t$ can be identified with a discrete simulation time step.

\subsection{Euler method}

The Euler equations are given by discretization of Eqs. (2)-(4):

$$
\begin{aligned}
& S_{n+1}=S_{n}-\beta S_{n} I_{n} \Delta t, \\
& I_{n+1}=I_{n}\left(1+\beta S_{n}-\gamma\right) \Delta t . \\
& R_{n+1}=R_{n}+\gamma I_{n} \Delta t .
\end{aligned}
$$

Population in one step ahead can easily be determined in very short time changes. To solve these equations, firstly $\beta$ and $\gamma$ ratios had to be known. An approximate prediction on infected and healthy people can be made by knowing these $\beta$ and $\gamma$ ratios for a fixed number of population in a defined time changes $[9,10]$.

\section{Results}

It is assumed that population is fixed in the $S I R$ model. $\beta$ values were calculated for each disease using the related values of previous two consecutive years. If the difference among the values of $\beta$ determined from the couples of the previous years is negligibly small, one of those can be used for the calculation procedure. Originally, each $\beta$ has to be used in the corresponding calculation procedure. In this study each $\beta$ for the mentioned calculation was used separately if the exact numbers were obtained, otherwise the same $\beta$ was used for the following years as can be seen from the Table, thus predicted results for 2013 and 2014 for the considered diseases were given. As mentioned before, the weakness of this model is unable to estimate the number of dead people so we cannot give the number of dead. All calculations were made by agreeing the population is 72 millions. Data were taken from Annual Report 2012 of Republic of Turkey Ministry of Health.

\subsection{Tuberculosis cases and predictions}

In this section, tuberculosis, as an epidemic disease, is considered. First, using the patients' population of the previous years, predictions of patients' population for the following years were obtained. These predictions and exact results were given in third and fourth line of Table I. It is seen that these results agree well with each other and it is seen that our prediction (estimated number) is very close to real case numbers (exact number) with the error being $2.5 \%$ or less. After these validation and verification we could have predicted the case numbers for 2013 and 2014.

TABLE I

Number of patients of tuberculosis cases and predictions.

\begin{tabular}{c|c|c|c|c|c}
\hline \hline year & $\begin{array}{c}\text { exact } \\
\text { number }\end{array}$ & $\begin{array}{c}\text { estimated } \\
\text { number }\end{array}$ & $\begin{array}{c}\text { error } \\
(\%)\end{array}$ & $\gamma$ & $\begin{array}{c}\beta \\
\text { (year range) }\end{array}$ \\
\hline 2010 & 15700 & - & - & - & $\begin{array}{c}- \\
1.26 \times 10^{-8} \\
(2010-2011)\end{array}$ \\
2011 & 14852 & 14864 & 0.1 & 0.96 & $1.31 \times 10^{-8}$ \\
2012 & 14430 & 14062 & 2.5 & 0.97 & $\begin{array}{l}(2011-2012) \\
1.31 \times 10^{-8} \\
(2011-2012)\end{array}$ \\
2013 & - & 13662 & - & 0.97 & $1.31 \times 10^{-8}$ \\
2014 & - & 12933 & - & 0.97 & $(2011-2012)$
\end{tabular}

\subsection{HIV/AIDS (acquired immune deficiency syndrome)}

The $S I R$ model was applied for the prediction of the HIV/AIDS patients' population in this section. Numerical results given in all lines except the last two lines of Table II, show the exact results and corresponding prediction obtained from the model SIR. As seen in Table II, the numerical result is almost the same with each other. The difference in exact numbers between 2011 and 2012 may imply an unexpected event that needs to be investigated. Therefore, the model gives us a chance to infer an excellent prediction from the data. It can be concluded that numerical results obtained from this model are also 
satisfying the trend of the exact data (i.e. while the exact given data are monotonically decrease (increase) by years, so are the estimated results).

TABLE II

Number of patients of HIV/AIDS cases and predictions.

\begin{tabular}{|c|c|c|c|c|}
\hline year & $\begin{array}{c}\text { exact } \\
\text { number }\end{array}$ & $\begin{array}{c}\text { estimated } \\
\text { number }\end{array}$ & $\gamma$ & $\begin{array}{c}\beta \\
\text { (year range) }\end{array}$ \\
\hline 2007 & 376 & - & - & - \\
\hline 2008 & 450 & 455 & 0.94 & $\begin{array}{l}1.58 \times 10^{-8} \\
(2007-2008)\end{array}$ \\
\hline 2009 & 528 & 536 & 0.90 & $\begin{array}{l}1.50 \times 10^{-8} \\
(2008-2009)\end{array}$ \\
\hline 2010 & 627 & 630 & 0.85 & $\begin{array}{l}1.44 \times 10^{-8} \\
(2009-2010)\end{array}$ \\
\hline 2011 & 699 & 701 & 0.89 & $\begin{array}{l}1.40 \times 10^{-8} \\
(2010-2011)\end{array}$ \\
\hline 2012 & 1068 & 1070 & 0.88 & $\begin{array}{l}1.96 \times 10^{-8} \\
(2011-2012)\end{array}$ \\
\hline 2013 & - & 1635 & 0.88 & $\begin{array}{l}1.96 \times 10^{-8} \\
(2011-2012)\end{array}$ \\
\hline 2014 & - & 2503 & 0.88 & $\begin{array}{l}1.96 \times 10^{-8} \\
(2011-2012)\end{array}$ \\
\hline
\end{tabular}

\subsection{CCHF (crimean-congo hemorrhagic fever)}

Similar explanations can also be mentioned for CCHF. It is very clear that the predictions are almost the same with the real case numbers as in the case of HIV/AIDS. It is interesting to see that the model $S I R$ is capable of mimicking the fluctuations in the numerical results before and after the year 2011 in Table III with high accuracy.

TABLE III

Number of patients of CCHF cases and predictions.

\begin{tabular}{|c|c|c|c|c|}
\hline year & $\begin{array}{c}\text { exact } \\
\text { number }\end{array}$ & $\begin{array}{c}\text { estimated } \\
\text { number }\end{array}$ & $\gamma$ & $\begin{array}{c}\beta \\
\text { (year range) }\end{array}$ \\
\hline 2008 & 1315 & - & 0.95 & $\begin{array}{l}2.48 \times 10^{-8} \\
(2007-2008)\end{array}$ \\
\hline 2009 & 1318 & 1315 & 0.95 & $\begin{array}{l}1.32 \times 10^{-8} \\
(2008-2009)\end{array}$ \\
\hline 2010 & 868 & 869 & 0.95 & $\begin{array}{l}8.46 \times 10^{-9} \\
(2009-2010)\end{array}$ \\
\hline 2011 & 1075 & 1074 & 0.94 & $\begin{array}{l}1.64 \times 10^{-8} \\
(2010-2011)\end{array}$ \\
\hline 2012 & 796 & 796 & 0.95 & $\begin{array}{l}9.60 \times 10^{-9} \\
(2011-2012)\end{array}$ \\
\hline 2013 & - & 589 & 0.95 & $\begin{array}{c}9.60 \times 10^{-9} \\
(2011-2012\end{array}$ \\
\hline 2014 & - & 437 & 0.95 & $\begin{array}{l}9.60 \times 10^{-9} \\
(2011-2012)\end{array}$ \\
\hline
\end{tabular}

\section{Conclusion}

If efficient precautions are not put into action, many people will be ineviTable affected by epidemic diseases, namely by social problems and deaths. In this framework, to minimize the negative effects of some epidemic diseases, which are AIDS, crimean-congo hemorrhagic fever and tuberculosis, their prospective prevalence was predicted by a mathematical modelling $S I R$.

Estimated data were well in concordance with the exact data. Moreover, we have predicted the number of infected people in 2013 and 2014 by using $\beta$ obtained from 2011-2012 data. Therefore, provided data in this project are very important to related institutions (Ministry of Health, hospitals etc.) to take precautions and for facing the situation in the future. Application of such studies gives hope to contribute country economics in terms of planning the drug, doctor, medical personnel etc. It will help to take precautions for prevention of progression of the diseases.

In this study three epidemic diseases were investigated using the epidemiological model $S I R$ and we predicted the number of infected people in 2013 and 2014 for these diseases. Analyzing the numerical results we concluded that the framework of the SIR model;

a) can predict the number of infected individuals well,

b) is sensitive to fluctuations in real data and able to predict the trend of the exact data,

c) gives result in a short time.

Our study is on progress to develop the SIR model and to apply it to other epidemic diseases and countries.

\section{References}

[1] Global tuberculosis report 2013, World Health Organization, 2013.

[2] O.J. Benedictow, The Black Death 1346-1353: The Complete History, Boydell Press, 2004.

[3] A.C. Steere, N. Engl. J. Med. 321, 586 (1989).

[4] H. Hilbi, S. Jarraud, E. Hartland, C. Buchrieser, Mol. Microbiol. 76, 1 (2010).

[5] M.L. Taff, F.P. Siegal, S.A. Geller, Am. J. Forensic Med. Pathol. 3, 259 (1982).

[6] A.J. Zuckerman, BMJ 7, 299 (1989).

[7] N. Masuda, P. Holme, F1000Prime Rep., Epub 2013 Mar 4.

[8] C. Drosten, S. Günther, W. Preiser, S. van der Werf, H.R. Brodt, S. Becker, H. Rabenau, M. Panning, L. Kolesnikova, R.A. Fouchier, A. Berger, A.M. Burguičre, J. Cinatl, M. Eickmann, N. Escriou, K. Grywna, S. Kramme, J.C. Manuguerra, S. Müller, V. Rickerts, M. Stürmer, S. Vieth, H.D. Klenk, A.D. Osterhaus, H. Schmitz, H.W. Doerr, N. Engl. J. Med. 348, 1967 (2003).

[9] W.O. Kermack, A.G. McKendrick, P. R. Soc. Lond. A 115, 700 (1927).

[10] M.J. Keeling, P. Rohani, Modeling Infectious Diseases in Humans and Animals, Princeton University Press, Princeton 2007. 